\title{
The Relationship Between Select Demographic Characteristics and Body Mass Index Among Native Hawaiian and other Pacific Islander Caregiving Adults
}

Katrina Duncan

Brigham Young University - Provo

Follow this and additional works at: https://scholarsarchive.byu.edu/etd

Part of the Nursing Commons

BYU ScholarsArchive Citation

Duncan, Katrina, "The Relationship Between Select Demographic Characteristics and Body Mass Index Among Native Hawaiian and other Pacific Islander Caregiving Adults" (2012). Theses and Dissertations. 3339.

https://scholarsarchive.byu.edu/etd/3339

This Thesis is brought to you for free and open access by BYU ScholarsArchive. It has been accepted for inclusion in Theses and Dissertations by an authorized administrator of BYU ScholarsArchive. For more information, please contact ellen_amatangelo@byu.edu. 
The Relationship Between Select Demographic Characteristics and Body Mass Index Among Native Hawaiian and Other Pacific Islander Caregiving Adults

\section{Katrina L. Duncan}

A thesis submitted to the faculty of

Brigham Young University

in partial fulfillment of the requirements for the degree of

Master of Science

Jane H. Lassetter, Chair

Gwen Van Servellen

Lora Beth Brown

College of Nursing

Brigham Young University

August 2012

Copyright (C) 2012 Katrina L. Duncan

All Rights Reserved 


\begin{abstract}
The Relationship Between Select Demographic Characteristics and Body Mass Index Among Native Hawaiian and Other Pacific Islander Caregiving Adults

\author{
Katrina L. Duncan \\ College of Nursing, BYU \\ Master of Science
}

Purpose: Native Hawaiian and other Pacific Islanders (NHOPIs) have the highest prevalence of overweight and obesity in the world. This study identified the proportion of our NHOPI sample in each body mass index (BMI) category and explored relationships between demographic characteristics and BMI. Design: This descriptive correlational study included 364 NHOPI caregiver adults in Utah $(n=155)$ and Hawaii $(n=209)$. We gathered demographic information with a questionnaire. Height and weight were measured for BMI calculations. Results:

According to the CDC's BMI categories, 84.3\% of our sample was overweight (BMI=25.0-29.9) or obese (BMI $\geq 30$ ). Participants in Utah had significantly higher BMIs than participants in Hawaii. Educational attainment was inversely related with BMI; age, gender, and income were not significantly related with BMI. Implications for practice: Clinicians should screen all NHOPIs for obesity and related risks. Future research should focus on culturally sensitive interventions and education to reduce obesity and associated risks among NHOPIs.
\end{abstract}

Keywords: NHOPI, Pacific Islander, Obesity, Body Mass Index, Demographics 


\section{TABLE OF CONTENTS}

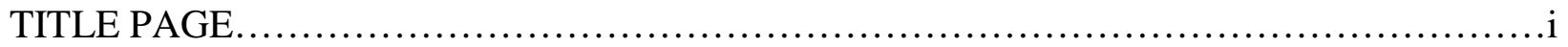

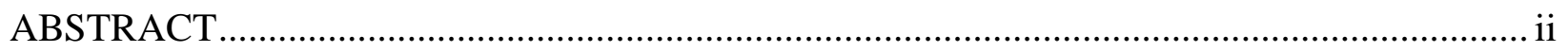

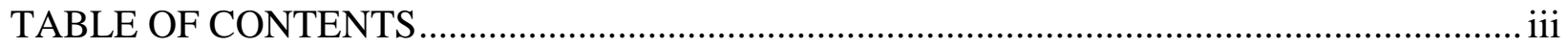

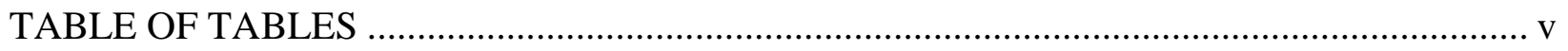

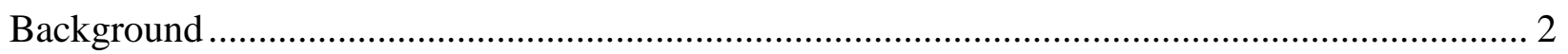

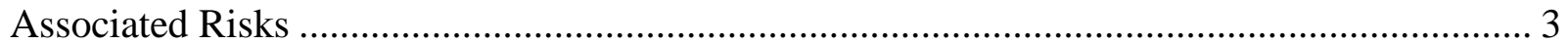

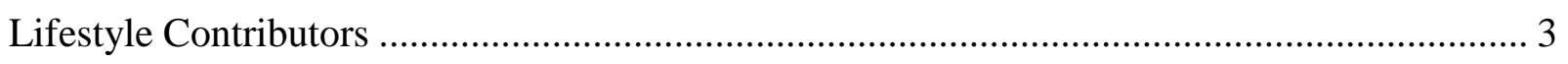

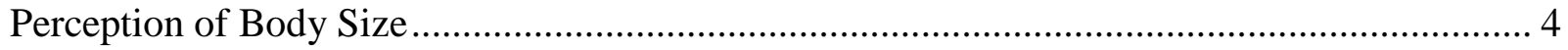

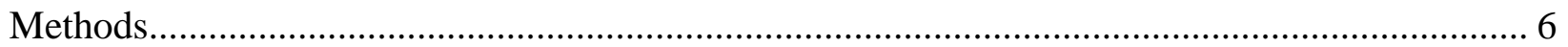

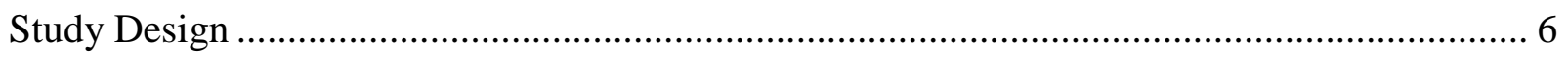

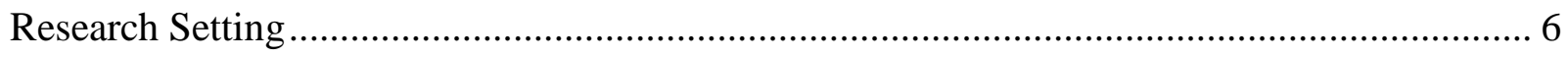

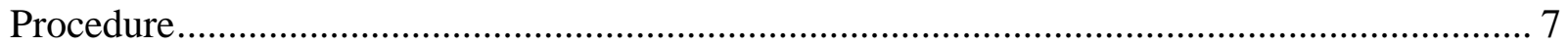

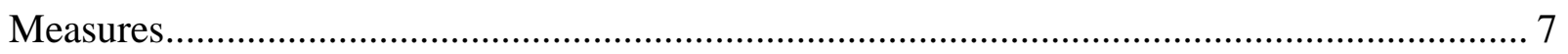

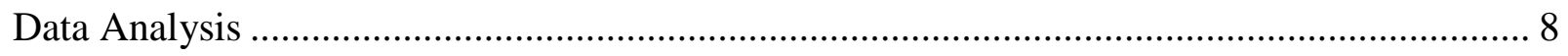

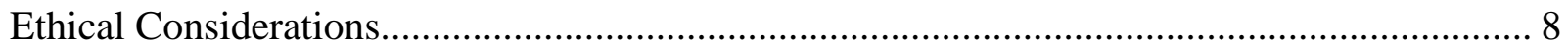

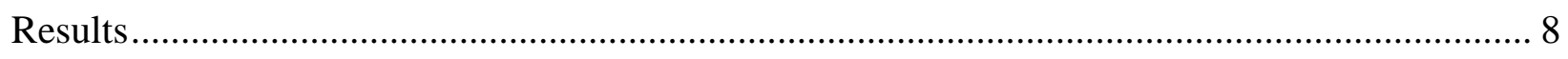

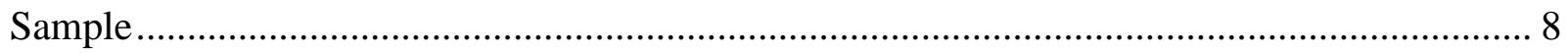

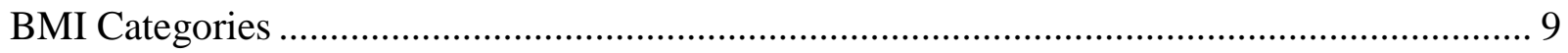

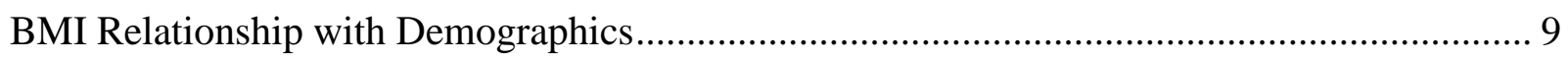

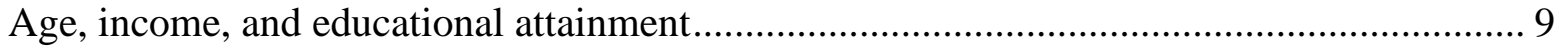

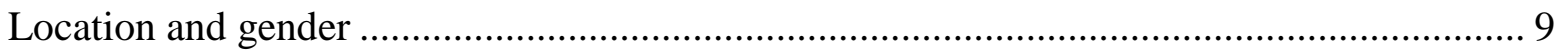

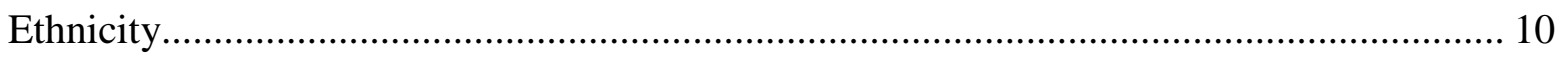

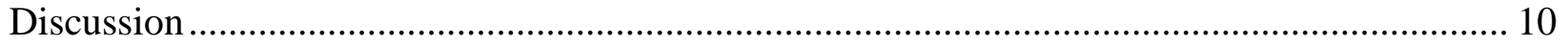

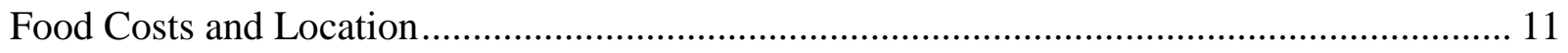

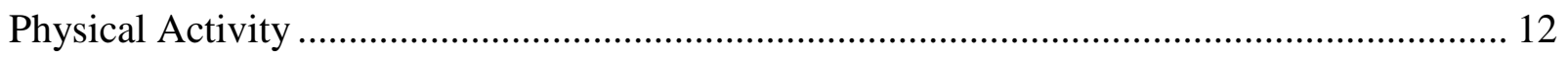

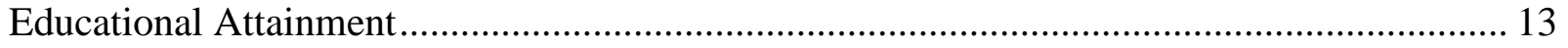

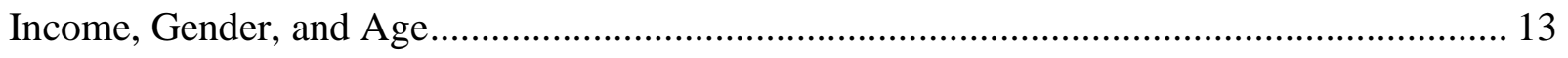

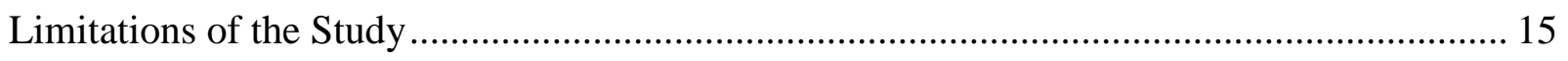

Implications for Clinical Practice and Future Research................................................... 16 


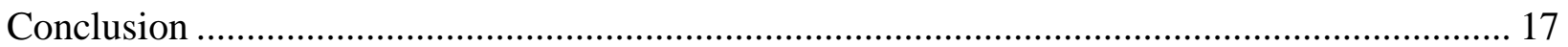

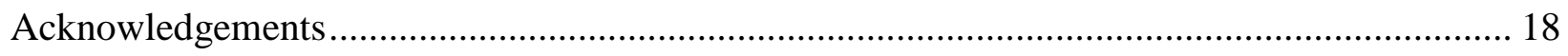

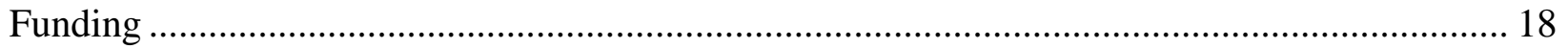

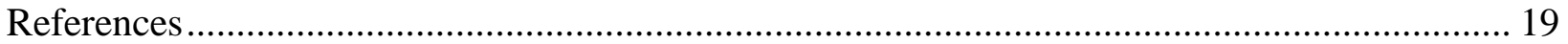




\section{TABLE OF TABLES}

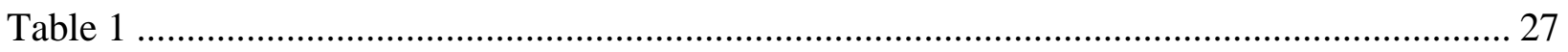

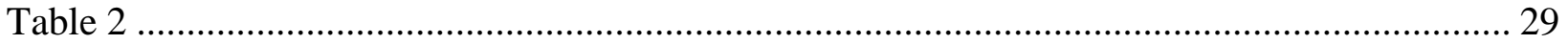

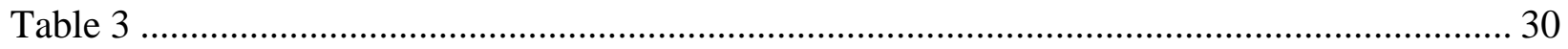

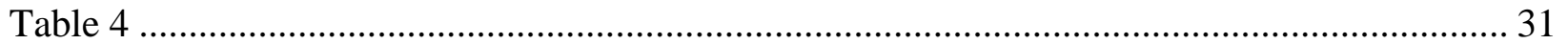

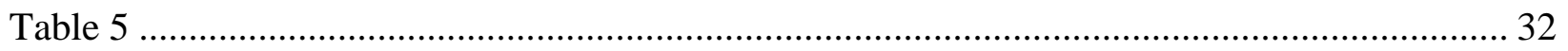

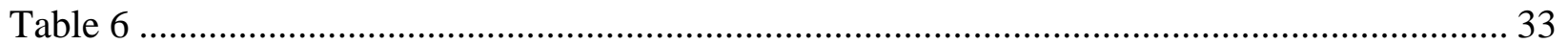


The Relationship Between Select Demographic Characteristics and Body Mass Index Among Native Hawaiian and Other Pacific Islander Caregiving Adults

Obesity is no longer a problem solely in developed nations. Though once an issue primarily affecting high-income countries, obesity is now a worldwide epidemic (World Health Organization [WHO], 2012). In fact, the term "globesity" has recently been applied to this vast public health problem (WHO, 2010). Currently, the WHO estimates 1.4 billion adults are overweight, and more than 500 million adults around the world are obese (WHO, 2012).

Obesity places a new burden on low- and middle-income countries already dealing with the burdens of infectious diseases and under-nutrition (WHO, 2012). The island nations of the Pacific Ocean exemplify this. Here, leading causes of morbidity and mortality have shifted to non-communicable diseases associated with obesity. Like many nations, Pacific Island nations struggle to find resources to deal with this growing burden (Seniloli, 2005).

Native Hawaiian or other Pacific Islanders (NHOPIs) include people with genetic origins in Hawaii, Samoa, or other Pacific Islands (Hixson, Hepler, \& Kim, 2012). NHOPI prevalence of overweight or obesity (body mass index $[\mathrm{BMI}] \geq 25 \mathrm{~kg} / \mathrm{m}^{2}$ ) is among the highest in the world. WHO global estimates for overweight or obesity prevalence is 93\% in Nauru, a Pacific Island nation considered the most obese country in the world. In comparison, the United States (U.S.) prevalence of overweight or obesity for all ethnicities is 68\% (Flegal, Carroll, Ogden, \& Curtin, 2010). Hawaii provides an interesting perspective, as it is both a Pacific Island and part of the U.S. Hawaii's overall prevalence of overweight or obesity is $52.1 \%$, but for Native Hawaiians living there, the prevalence is 69.6\% (Hawaii Department of Health, 2009). Inasmuch as NHOPIs are one of the fastest growing ethnic groups in the U.S. (Chiem et al., 2006) and their 
overweight and obesity prevalence is high, the U.S. as well as Pacific Island nations must increasingly be concerned with obesity and related health care issues.

Traditionally, NHOPIs have been aggregated with Asians, making it difficult to identify their unique issues. Advocacy groups for NHOPIs have called for research specific to NHOPIs to address their particular needs (Stafford, 2010). Recent studies examined NHOPI obesity and its relationship to health behaviors and risks, but included limited information on sample demographics (Hughes \& Marks, 2009; Moy, Sallis, Ice, \& Thompson, 2010). The Centers for Disease Control and Prevention (CDC; 2010) showed that obesity prevalence varies substantially by race/ethnicity, location, gender, and education. However, these data were not NHOPI specific and were self-reported. A systematic search of the literature from 2001 to 2012 revealed no studies directly exploring the relationship of NHOPI demographic characteristics and BMI.

In order to address the burden of NHOPI obesity, it is necessary to better understand the relationship between demographic characteristics and accurately measured BMI within a sample of NHOPIs. Thus, the purposes of this study are to identify the proportion of the sample that is overweight or obese and explore the relationship between BMI and demographic characteristics in a sample of NHOPI caregiving adults.

\section{Background}

Statistics demonstrate NHOPIs generally have higher levels of overweight and obesity than much of the world's population (WHO, 2011). The implications of these statistics are best understood by examining the associated risks of obesity and factors contributing to NHOPIs' high prevalence of obesity, including lifestyle and perception of body size. 


\section{Associated Risks}

Obesity is linked to a plethora of health risks; as obesity increases, so does morbidity and mortality of related non-communicable diseases. Individuals, communities, and nations deal with the burden of providing the associated costly healthcare. Obesity increases the risk for cardiovascular disease, stroke, hypertension, type 2 diabetes, and some cancers (CDC, 2010; Davis et al., 2004; Metcalf, Scragg, Willoughby, Finau, \& Tipene-Leach, 2000; WHO, 2012). Obesity also correlates with psychological disorders, osteoarthritis, sleep apnea, respiratory problems (Davis et al., 2004), and gestational diabetes (Kim et al., 2010).

The Pacific Islands have experienced these obesity-related disease patterns. Degenerative, non-communicable, and chronic diseases are outpacing infectious diseases. The number of NHOPI adults dying prematurely is significantly higher than other populations. Most NHOPIs die from diabetes, coronary disease, and vascular disease, each of which is related to obesity (Seniloli, 2005). Nauru not only has the highest prevalence of obesity in the world, it also has the highest prevalence of diabetes (Seniloli, 2005; WHO, 2011). Similarly, among all ethnic groups in Hawaii, Native Hawaiians have the highest prevalence of diabetes and a diabetesrelated mortality three times higher than Caucasians. Native Hawaiians also have a cardiovascular disease mortality that is more than twice that of Japanese inhabitants, who have the lowest rate in Hawaii (Mau, Sinclair, Saito, Baumhofer, \& Kaholokula, 2009). As obesity prevalence grows, so does the prevalence and impact of these obesity-related diseases.

\section{Lifestyle Contributors}

Universally, shifting diets and changing physical activity contribute to "globesity.” These same trends are seen in NHOPIs. Their diets once consisting of traditional foods, such as breadfruit, banana, yam and taro, have transitioned to calorie-dense diets with increased animal 
fat, sugars, salt and processed foods. This may be due to increased availability of calorie-dense foods, a change in tastes, and increased incomes that allow such food purchases (Hughes \& Marks, 2009; Seniloli, 2005; Snowdon, Lawrence, Schultz, Vivili, \& Swinburn, 2010). Increased obesity prevalence may also be related to activity change in both employment and recreation. New types of employment require less physical labor (Seniloli, 2005). Specifically in the Pacific Islands, urbanization has increased sedentary occupations, moving from the highly physical labor of farming and fishing to less active roles in office, retail, and tourism settings. Additionally, modern technology has reduced the physical activity and energy expenditure required in many jobs (Gill et al., 2002).

A similar transition has occurred in recreational activities. Recreation in the Pacific Islands has historically included dancing, beach walks, canoeing, and swimming (Siefken, Macniven, Schofield, Bauman, \& Waqanivalu, 2011). Modern sedentary activities, such as television and video games, now dominate many lifestyles. Physical activity is not only influenced by increased sedentary activity, but also by limited recreational facilities, cost, and demographic factors (Moy et al., 2010). In the Pacific Islands, increased violence and crime have led to safety concerns, which discourage certain types of physical activity. For example, people who do not feel safe in their neighborhood are less likely to exercise outside (Gill et al., 2002). Generally, NHOPIs are less active than their Caucasian counterparts; in the U.S., NHOPIs have a greater risk than other Americans for inactivity-related conditions, such as obesity and diseases like cardiovascular disease, type 2 diabetes, and some cancers (Moy et al., 2010).

\section{Perception of Body Size}

When examining obesity among NHOPIs, the perception and value of body size should be considered. Some NHOPIs perceive a fuller, even obese, figure as desirable (Chiem et al., 
2006; Lassetter, 2011; Metcalf et al., 2000; Pollock, 1995; Seniloli, 2005). Historically, large body size was considered beautiful and signified wealth, status, and prestige (Davis et al., 2004; Gill et al., 2002; Lassetter, 2011). However, this traditional large body size implied a musculature and strength that offered protection and stamina during hard physical labor, periods of starvation, and infectious diseases. The current large body size is more often due to fat, likely from changing diets and lifestyles. Thus, large body size has become more harmful than protective (Gill et al., 2002; Lassetter, 2011).

Some researchers have examined NHOPIs’ perceptions of body size (Davis et al., 2004). In Australia, overweight Samoan women felt more attractive, stronger, and fitter than their overweight Australian counterparts (Wilkinson, Ben-Tovim, \& Walker, 1994). Likewise, overweight Samoan women in New Zealand did not perceive themselves as overweight and did not have negative views of obesity (Brewis, McGarvey, Jones, \& Swinburn, 1998). In Hawaii, researchers found differences in body image perceptions depending on whether NHOPIs identified with Pacific Island culture or Western culture. Participants who identified more with Western culture perceived the ideal body size as slimmer than participants who identified more with Pacific Island culture (Wang, Abbott, Goodbody, \& Hui, 2002). Additionally, NHOPIs in Hawaii were more accepting of larger body size than their White and Asian-American counterparts (Chang et al., 2000).

The prevalence of obesity among NHOPIs and increased morbidity and mortality associated with obesity-related diseases have become great health concerns. Clinicians are in a position to address obesity issues in a variety of patient populations, including NHOPIs. To better understand the needs of NHOPIs, one first needs to understand the BMI distribution among NHOPIs. Further, an understanding of risk among various subgroups based upon 
demographics may lead to more efficient screening of high-risk groups in need of health promotion and teaching.

\section{Methods}

\section{Study Design}

This study is part of a larger study investigating caregiving patterns and food label literacy in NHOPI caregiving adults. We used a descriptive correlational design and convenience, purposeful sampling. We developed the portion of the questionnaire related to this study, including demographic questions, such as gender, location, age, income, educational attainment, ethnicity, and marital status.

\section{Research Setting}

Data collection occurred in Utah and Hawaii. In Utah, which has one of the highest concentrations of NHOPIs in the U.S. outside Hawaii (Hixson et al., 2012), recruitment and data collection occurred in Salt Lake and Tooele counties at these events: the NHOPI Memorial Day Celebration, Samoan Flag Day, and a NHOPI Health Summit. NHOPI community leaders helped identify cultural events with a high likelihood of successful recruitment and data collection, and helped recruit participants at the events. In Hawaii, settings included a preschool and supermarkets around Oahu and the Big Island of Hawaii, in neighborhoods of varying socioeconomic levels. Two local Native Hawaiian research assistants helped identify locations frequented by NHOPIs who might be willing to participant and helped recruit participants at those locations. Managers at each event or location gave signed permission before recruitment or data collection occurred. 


\section{Procedure}

Participants were recruited using fliers that briefly stated the purpose, inclusion criteria, and the researcher's contact information. Researchers set up tables at the events, and recruits were given the fliers when they approached the tables. Participants met the following inclusion criteria: (1) self-identification as NHOPI or as a member of a NHOPI subgroup, such as (but not limited to) Native Hawaiian, Tongan, Samoan, or other Pacific Islander, (2) ability to speak English, and (3) role of primary caregiver (e.g. parent, aunt, uncle, or grandparent) of a NHOPI child between 6 months and 18 years of age. The last criterion, being a caregiver, was included for purposes of the larger study using the same questionnaire.

After having the study explained and any questions answered, people who met inclusion criteria and wanted to participate were asked to read and sign a consent form. Then the researcher or research assistants read the questions to participants and recorded their answers in writing. After completing the questionnaire, participants' height and weight were measured and recorded. Participants were compensated for their time. Children accompanying participants were entertained with coloring books during the questionnaire and measurements.

\section{Measures}

Height and weight were measured at the interview site. Height was measured with a Seca 213 Stadiometer. Weight was measured with participants fully clothed using a digital Seca 803 scale. To increase reliability and validity, each participant was weighed twice. If the two measurements differed, a third measurement was taken, and all three results were averaged for use in data analysis.

BMI (mass in kilograms divided by the square of the height in meters) was calculated from these measurements using the CDC's (2011b) on-line adult BMI calculator. Categories for 
BMI in this study are those classified by the CDC: underweight (BMI $<18.5 \mathrm{~kg} / \mathrm{m}^{2}$ ), normal weight (BMI $\geq 18.5 \mathrm{~kg} / \mathrm{m}^{2}$ but $<25 \mathrm{~kg} / \mathrm{m}^{2}$ ), overweight $\left(\mathrm{BMI} \geq 25 \mathrm{~kg} / \mathrm{m}^{2}\right.$ but $\left.<30 \mathrm{~kg} / \mathrm{m}^{2}\right)$, and obese (BMI $\geq 30 \mathrm{~kg} / \mathrm{m}^{2}$ ). A subcategory of obesity, morbidly obese, was also included for participants with a BMI greater than or equal to $40 \mathrm{~kg} / \mathrm{m}^{2}$ (CDC, 2011a).

\section{Data Analysis}

Data were analyzed using IBM Statistical Package for the Social Sciences Statistics (SPSS) Version 19 software. A significance of $\mathrm{p}<.05$ was established. We calculated descriptive statistics (means, standard deviations, medians, and ranges for continuous variables, and frequencies for dichotomous and nominal variables). To examine the relationship of age, income, and educational attainment with BMI, correlations were completed. Two-tailed t-tests were used to examine BMI differences among gender and location. Finally, a one-way analyses of variance (ANOVA) was done to explore how ethnic subgroup differences were associated with BMI. An expert nurse statistician was consulted to ensure accurate and optimal analysis.

\section{Ethical Considerations}

Institutional Review Boards at Brigham Young University, Brigham Young UniversityHawaii, and the University of Utah approved this study. Questionnaires and body measurements were conducted as privately as circumstances allowed, and confidentiality was carefully guarded. For example, consent forms and questionnaires were stored separately to protect confidentiality.

\section{Results}

\section{Sample}

Our sample included 364 NHOPIs, 42.6\% $(n=155)$ in Utah and 57.4\% $(n=209)$ in Hawaii. Ages of participants ranged from 18 to $85(M=39.0$ years, $S D=15.2)$ and the sample was $64.0 \%$ female. Demographic information for the study sample is detailed in Table 1. 


\section{BMI Categories}

Participants’ weights ranged from $29.0 \mathrm{~kg}$ to $190.0 \mathrm{~kg}(M=93.0, S D=25.9)$.

Participants’ heights ranged from 115.6 centimeters to 194.3 centimeters $(M=168.1, S D=9.7)$.

Table 2 shows the division of participants into BMI categories. Overall, 84.3\% of our NHOPI sample was overweight or obese. Of those, 58.5\% were obese, including $16.7 \%$ who were morbidly obese.

\section{BMI Relationship with Demographics}

Age, income, and educational attainment. The resulting correlations of age, income, and educational attainment are shown in Table 3. Correlations of BMI with age $(r=.031 ; \mathrm{p}=$ $.560)$ and income $(r=-.055 ; \mathrm{p}=.299)$ were not statistically significant. However, the correlation between educational attainment and BMI was significant $(r=-.123 ; p<.05)$. This means that as participants’ education increased, their BMI decreased slightly. Education explained approximately $1 \%$ of the variance in BMI.

Location and gender. The relationship between location and BMI was statistically significant. These results are detailed in Table 4. The BMI of participants in Utah was significantly greater than the BMI of participants in Hawaii $(\mathrm{p}=.017)$.

Examining BMI distribution by gender yields further insight. Prevalence of overweight or obesity (see Table 2) among male participants was 90.9\%, of which 69.5\% were obese and 17.6\% were morbidly obese. Female participants had a lower prevalence of overweight or obesity at $80.7 \%$ with obesity prevalence alone of $52.4 \%$, including $16.7 \%$ who were morbidly obese. 
Table 5 shows the relationship between BMI and gender. Males in our sample had a greater mean BMI $(M=33.49, S D=7.12)$ than females $(M=32.06, S D=8.34)$. However, this difference was not statistically significant $(p=.086)$.

We also compared females and males by location (see Table 4). The BMI of male participants in Utah $(M=34.77, S D=7.18)$ was significantly higher $(\mathrm{p}=.039)$ than males in Hawaii $(M=32.20, S D=6.93)$. Although female participants in Utah had higher BMI $(M=$ 32.96, $S D=8.0)$ than their female counterparts in Hawaii $(M=31.50, S D=8.28)$, the difference was not statistically significant $(\mathrm{p}=.195)$.

Ethnicity. During the interview, participants were asked to self-identify as Native Hawaiian, Samoan, Tongan, or other Pacific Islander. Using ANOVA to examine BMI within these ethnic subgroups (see Table 6), we found that Samoans had a significantly greater BMI than Hawaiians $(\mathrm{p}=.00)$ and other Pacific Islanders $(\mathrm{p}=.00)$ but not significantly greater than Tongans $(\mathrm{p}=.09)$. Within the Samoan subgroup, we found that fewer than expected participants were in the normal weight category of BMI $(n=2$, expected $n=10.7)$, and more than twice as many as expected were morbidly obese ( $n=25$, expected $n=12.3)$.

\section{Discussion}

The prevalence of overweight or obesity of NHOPIs as found in our study is similar to the most recent WHO global estimates of Pacific Island nations. The six highest prevalence for male overweight and obesity in the world are Pacific Island nations, ranging from $80.9 \%$ to 96.9\%. For female overweight and obesity prevalence, the top seven nations are Pacific Islands and the range is $84.1 \%$ to $93.1 \%$ (WHO, 2011). The prevalence of overweight or obesity, and obesity alone, in our sample of NHOPIs is comparable to the heaviest Pacific Island nations. 
More specifically, in comparing studies of Native Hawaiians, the NHOPI prevalence of overweight and obesity found in our study of $84.3 \%$ is much higher than that found in a 2009 Hawaiian Health Survey of 69.6\%, based on self-reported height and weight (Hawaii Department of Health, 2009). This disparity may suggest the importance of using carefully measured height and weight to accurately determine BMI in population studies. Research has shown that in selfreported data, weight is often under-reported and height over-reported, leading to underestimated BMI (Elgar \& Stewart, 2008). To understand the full extent of obesity in NHOPIs and associated risks, researchers should use accurately measured heights and weights to help reach the most accurate conclusions.

\section{Food Costs and Location}

In a recent survey, 73\% of U.S. respondents reported price influenced their food purchase decisions. Taste of the food was the only higher consideration, with $87 \%$ of respondents using it to make food-purchase decisions. Only $61 \%$ of U.S. respondents thought healthfulness was an important consideration in making food purchases (International Food Information Council Foundation, 2012). Over the last 30 years, prices of fruits and vegetables have increased, while the costs of less healthy, calorie-dense, processed foods have decreased (Finkelstein \& Strombotne, 2010). The cost of food affects the intake of food; over the last 30 years, both men and women have also increased their daily calorie intake, trending with the obesity epidemic (Wright, Kennedy-Stephenson, Wang, McDowell, \& Johnson, 2004).

Food prices vary with location, and are generally more expensive in remote locations than in the U.S. mainland. The small size and remoteness of Hawaii and other Pacific Islands mean much of the food (85-90\%) must be imported over great distances, making food costly (Hawaii Department of Agriculture, 2008). According to the U.S. Department of Agriculture 
(USDA; 2012a), in 2011, cost of food on a thrifty plan for a family of four averaged $\$ 543.50$ per month in the U.S. mainland. In comparison, this same plan costs almost twice as much in Hawaii at \$1038.00 (USDA, 2012b). This difference in food costs may help explain the significantly higher BMI of NHOPIs in Utah than Hawaii.

When NHOPIs move from Hawaii to the U.S. mainland, their food budget stretches further. In fact, Native Hawaiian migrants in Las Vegas explained they ate more food in Las Vegas than they had in Hawaii because groceries and restaurants were less expensive in Las Vegas. The ability to purchase more food and the tendency to over-eat contributed to the selfreported larger body size of Native Hawaiians in Las Vegas (Lassetter, 2011). These dietary patterns then influence the dietary patterns of migrants’ posterity because these are learned in the context of families (Gruber \& Haldeman, 2009). Thus, though our sample was not strictly firstgeneration migrants, the relatively lower cost of food likely contributed to a higher mean BMI in Utah than in Hawaii.

\section{Physical Activity}

Physical activity may also contribute to the significant difference between NHOPI BMI in Utah and Hawaii. Utah’s climate is very different than that of the Pacific Islands; Utah’s winters are cold and long. Such conditions may encourage increased time indoors, especially for those more accustomed to warmer temperatures, thus decreasing outdoor physical activity. In a study that examined physical activity levels of Tongans in Utah, only $20 \%$ met the physical activity recommendations of the U.S. Department of Health and Human Services (Behrens, Moy, Dinger, Williams, \& Harbour, 2011). Acculturation also influences activity. Some immigrants arrive in the U.S. with good physical activity and dietary patterns but these patterns progressively worsen over time in the U.S. (Lassetter \& Callister, 2009). A greater understanding of the 
relationship of increased BMI in the U.S. can be obtained through future research focusing on a comparison of NHOPI physical activity and dietary patterns in a native land and in the U.S.

\section{Educational Attainment}

Another significant demographic variable in our study, educational attainment, may influence BMI for several reasons. People with higher levels of education are more likely to have additional information about health risks associated with obesity, and a greater understanding of the benefits of healthy eating and exercising. A multi-ethnic study in Hawaii showed a significant inverse relationship between educational attainment and BMI in women but not men (Brown, Hampson, Dubanoski, Stone Murai, \& Hillier, 2009). Several researchers found a significant inverse relationship between BMI and educational attainment in many populations, including Finnish, Caucasian, African-American, and others (Himes \& Reynolds, 2005; SarlioLahteenkorva, Silventoinen, \& Lahelma, 2004; Worthy, Lokken, Pilcher, \& Boeka, 2010). Himes \& Reynolds (2005) retrospectively examined data from the National Health Interview Survey in the U.S.; their results showed that although a relationship still existed between BMI and educational attainment, the strength of the relationship has declined over time. As the adult population became increasingly educated, obesity rates continued to climb rather than decline as expected. Educational attainment is associated with lower BMI levels in our sample, but education’s influence was minimally significant, explaining only 1\% of BMI variance.

\section{Income, Gender, and Age}

Our findings suggest that income, gender, and age do not contribute significantly to the high prevalence of obesity among NHOPIs. Current research is conflicted over the relationship of obesity and income in other populations. Jolliffe (2011) noted the relationship of obesity and income is commonly portrayed in media, policy briefings, and some academic writing as a 
significantly negative correlation. Indeed, studies support this portrayal (Berry et al., 2010; Choi, Guiterrez, Gilliss, \& Lee, 2011). However, Jolliffe completed an extensive analysis of the National Heath and Nutrition Examination Survey (NHANES) in the U.S. from 2003 to 2006 and found no statistically significant difference between poor and non-poor people in overweight or obesity prevalence. Interestingly, when research is focused on low- or middle-income countries (LMICs), several researchers found a significant, positive relationship between obesity and income (Fernald, 2007; Neuman, Finlay, Smith, \& Subramanian, 2011; Subramanian, Perkins, Ozaltin, \& Smith, 2011). Many Pacific Island nations are LMICs, so it may be beneficial to focus further research on these NHOPI populations to identify if they too demonstrate a significant, positive relationship between income and obesity. Our sample is similar to the NHANES sample Jolliffe analyzed, consisting of a range of incomes in a developed country; thus, we may conclude that NHOPIs in Utah and Hawaii trend with their U.S. counterparts in the lack of a significant relationship between income and obesity.

Our NHOPI sample may be unique in its lack of a significant relationship between BMI and gender or age. Researchers studying multi-ethnic samples in the U.S. and Australia found males were more likely to have greater BMIs than females (Christian, Giles-Corti, Knuiman, Timperio, \& Foster, 2011; Flegal et al., 2010; Hedley et al., 2004; Kifle \& Desta, 2012). Likewise, researchers have found a significant relationship between age and BMI. In multiethnic samples, this relationship represented a concave curve. BMI increased with age initially, but then decreased later in life (Berry et al., 2010; Kifle \& Desta, 2012). Because our study was not longitudinal, we cannot conclude whether our sample would follow a similar trend. However, BMI was not significantly correlated with age in our study. This is concerning because NHOPIs in early adulthood had high BMIs; overtime this situation could worsen without intervention. 
Also, obesity early in adulthood is associated with increased risk of mortality and morbidity (Zimmerman, Holst, \& Sorenson, 2011). Overall, our findings highlight the great complexity of obesity. Especially in the NHOPI population, demographic characteristics can only explain a fractional part of the obesity issue, which is influenced by culture, genetics, perceptions, habits, and tradition.

\section{Limitations of the Study}

The sampling method was a limitation in this study; we used convenience, purposeful sampling, which may introduce sampling bias by attracting those with a particular interest in nutrition and health. In an effort to minimize bias, we collected data at a variety of events and locations. These recruitment locations also reflected a variety of differing socio-economic statuses.

In order to qualify for participation, the recruits had only to self-identify as NHOPI; we had no criteria for a percentage of NHOPI ethnicity. Thus, the results must be considered with the understanding that not all participants were of strictly NHOPI descent. Several participants in our sample were of multiple ethnicities. This is, however, reflective of NHOPIs in the U.S., who are the most likely among race groups to report multiple races (Hixson et al., 2012). The distribution of ethnic subgroups among our sample should be noted. Samoan represented 20.3\% of our sample, but Tongans represented only 6\%. This may have influenced our findings when comparing the ethnic subgroups.

The inclusion criterion of being a primary caregiver of children may have limited those who could participate in this study. Though this criterion was critical to the larger study, we may have had a broader sample without this criterion. 
Another limitation was that we did not exclude pregnant women. Because of weight gain during pregnancy, pregnant participants may have affected our BMI results. We asked no questions regarding pregnancy, so we do not know how many participants may have been pregnant.

The use of BMI as an optimal measurement of obesity is debatable. Although BMI historically has been used to diagnose obesity, its use is criticized for its uncertain ability to differentiate between fat mass and lean muscle mass and to assess fat distribution (Stevens, McClain, \& Truesdale, 2008). Romero-Corral et al. (2008) found the obese classification of BMI $\geq 30$ has excellent specificity; most people in the obese category are properly categorized. However, more than $50 \%$ of people with excess body fat are under-classified due to height and weight measurements that place their BMI into a normal or overweight category. On the other hand, people with greater amounts of heavy muscle mass may be misclassified as obese. More precise measurements than height and weight to calculate BMI may be advantageous in an individual setting in determining disease etiology and risk. However, BMI is less expensive and more feasible than more precise measures of adiposity, such as skin-fold measures, especially in population studies. Therefore, BMI remains the most commonly used measurement in studying the health consequences of obesity (Stevens et al., 2008). Each of these limitations should be considered pertaining to the application of this study.

\section{Implications for Clinical Practice and Future Research}

Due to the widespread prevalence of obesity across demographics in the NHOPI population, healthcare providers should properly screen NHOPIs for overweight and obesity and the associated risks. Individuals should be assessed with other obesity indicators, such as waist circumference and skin-fold measurements, not solely BMI. Healthcare providers should seek to 
educate on risks of obesity while maintaining a cultural sensitivity of NHOPIs values; strategies focusing on good nutrition and “activity” may be more acceptable than a focus on weight loss and “exercise.” NHOPIs in their native lands, in the U.S., and around the world would benefit from nutrition education on healthy food options and activity. Because of the collectivist culture of NHOPIs (McLaughlin \& Braun, 1998), a focus on the family or community as a group may enhance the effectiveness of these education efforts. In addition, NHOPIs may be more receptive to NHOPI instructors and facilitators, suggested by the crucial role of NHOPI research assistants and community leaders in recruitment of our participants.

Considering the significant findings of Samoans in our study, researchers need to examine why Samoans are at an increased risk for obesity than other NHOPI subgroups. In addition, the effectiveness of interventions, such as nutrition education and activity, should be researched in the NHOPI population. This will help identify the best approach to control and decrease the obesity epidemic among this high-risk group.

\section{Conclusion}

Obesity is a complex issue with numerous contributors. NHOPIs are one of the most obese groups in the world and consequently are at very high risk for associated morbidity and mortality. The obesity epidemic in NHOPIs is widespread, affecting people of all ages and income levels and both genders. Education offers a small advantage, as a higher educational attainment is correlated with lower BMI among NHOPIs, but this explains only a fractional part of the issue. NHOPI BMI is also influenced by location; those living in areas of low food prices may be at an increased risk for obesity. With this greater understanding of the contributors of obesity, we can better direct education, interventions, and our clinical practice towards improving health of NHOPIs. 


\section{Acknowledgements}

I would like to thank all participants involved in this study for their willingness to participate and contribute their time and effort. I would also like to express gratitude to Charles Sale Ah You and Joyce Samalaulu Ah You at the Queen Center in Utah, and Jonathan Cummings, Barbara Hanohano, and Shemnon Miyamoto in Hawaii, for their assistance with recruitment and site arrangement. Members of my thesis committee included Jane H. Lassetter, PhD, RN, Gwen Van Servellen, PhD, RN, FAAN, and Lora Beth Brown, PhD, RD.

\section{Funding}

This study was made possible through a Brigham Young University Mentoring Environment Grant and two Graduate Mentoring Grants from Brigham Young University. 


\section{References}

Behrens, T. K., Moy, K., Dinger, M. K., Williams, D. P. \& Harbour, V. (2011). Objectively assessed physical activity among Tongans in the United States. Research Quarterly for Exercise and Sport, 82(3), 565-569.

Berry, T. R., Spence, J. C., Blanchard, C., Cutumisu, N., Edwards, J., \& Nykiforuk, C. (2010). Changes in BMI over 6 years: The role of demographic and neighborhood characteristics. International Journal of Obesity, 34(8), 1275-1283. doi:10.1038/ijo.2010.36

Brewis, A. A., McGarvey, S. T., Jones, J., \& Swinburn, B. A. (1998). Perceptions of body size in Pacific Islanders. International Journal of Obesity and Related Metabolic Disorders: Journal of the International Association for the Study of Obesity, 22(2), 185-189.

Brown, D. E., Hampson, S. E., Dubanoski, J. P., Stone Murai, A., \& Hillier, T. A. (2009). Effects of ethnicity and socioeconomic status on body composition in an admixed, multiethnic population in Hawaii. American Journal of Human Biology, 21, 383-388.

Centers for Disease Control and Prevention. (2010). Vital signs: State-specific obesity prevalence among adults -- United States, 2009. MMWR: Morbidity \& Mortality Weekly Report, 59(30), 951-955.

Centers for Disease Control and Prevention. (2011a). About BMI in adults. Retrieved from http://www.cdc.gov/healthyweight/assessing/bmi/adult_bmi/index.html

Centers for Disease Control and Prevention. (2011b). Adult BMI calculator. Retrieved from http://www.cdc.gov/healthyweight/assessing/bmi/adult_bmi/english_bmi_calculator/bmi _calculator.html 
Chang, H. K., Grandinetti, A., Lan, G., Rodriguez, B. L., Melish, J. S., \& Curb, J. D. (2000). Cross-cultural comparisons of ideal body type among a multi-ethnic population in Hawaii. Diabetes, 49(suppl 1), A182.

Chiem, B., Nguyen, V., Wu, P. L., Ko, C. M., Cruz, L. A., \& Sadler, G. R. (2006). Cardiovascular risk factors among Chamorros. BMC Public Health, 6, 298-298. doi:10.1186/1471-2458-6-298

Choi, J., Guiterrez, Y., Gilliss, C., \& Lee, K. A. (2011). Body mass index in multiethnic midlife women: Influence of demographic characteristics and physical activity. Health Care for Women International, 32(12), 1079-1087. doi:10.1080/07399332.2011.562998

Christian, H., Giles-Corti, B., Knuiman, M., Timperio, A., \& Foster, S. (2011). The influence of the built environment, social environment and health behaviors on body mass index. Results from RESIDE. Preventative Medicine, 53, 57-60. doi:10.1016/j.ypmed. 2011.05.004

Davis, J., Busch, J., Hammatt, Z., Novotny, R., Harrigan, R., Grandinetti, A., \& Easa, D. (2004). The relationship between ethnicity and obesity in Asian and Pacific Islander populations: A literature review. Ethnicity \& Disease, 14(1), 111-118.

Elgar, F. J., \& Stewart, J. M. (2008). Validity of self-report screening for overweight and obesity. Evidence from the Canadian Community Health Survey. Canadian Journal of Public Health, 99(5), 423-427.

Fernald, L. C. (2007). Socio-economic status and body mass index in low-income Mexican adults. Social Science \& Medicine, 64(10), 2030-2042. doi:10.1016/j.socscimed. 2007.02.002 
Finkelstein, E. A., \& Strombotne, K. L. (2010). The economics of obesity. The American Journal of Clinical Nutrition, 91(5), 15205-15245. doi:10.3945/ ajcn.2010.28701E

Flegal, K. M., Carroll, M. D., Ogden, C. L., \& Curtin, L. R. (2010). Prevalence and trends in obesity among US adults, 1999-2008. JAMA: The Journal of the American Medical Association, 303(3), 235-241. doi:10.1001/jama.2009.20

Gill, T., Hughes, R., Tunidau-Schultz, J., Nishida, C., Galea, G., \& Cavalli-Sforza, T. (2002). Obesity in the Pacific: Too big to ignore. Retrieved from http://www.wpro.who.int/NR/ rdonlyres/B924BFA6-A061-43AE-8DCA-0AE82A8F66D2/0/obesityinthepacific.pdf

Gruber, K. J., \& Haldeman, L. A. (2009). Using the family to combat childhood and adult obesity. Preveting Chronic Disease, 6(3), A106. Retrieved from http://www.cdc.gov/pcd/ issues/2009/jul/08_0191.htm

Hawaii Department of Agriculture. (2008). Food self sufficiency in Hawaii. Retrieved from http://hawaii.gov/hdoa/add/White\%20Paper\%20D14.pdf

Hawaii Department of Health. (2009). Hawaii health survey 2008. Retrieved from http://hawaii. gov/health/statistics/hhs/hhs_08/hhs08t31.pdf

Hedley, A., Ogden, C., Johnson, C., Carroll, M., Curtin, L., \& Flegal, K. (2004). Prevalence of overweight and obesity among U.S. children, adolescents, and adults, 1999-2002. Journal of the American Medical Association, 291, 2847-2850. doi:10.1001/jama.291.23.2847

Himes, C. L., \& Reynolds, S. L. (2005). The changing relationship between obesity and educational status. Gender Issues, 22(2), 45-57. doi:10.1007/s12147-005-0014-2

Hixson, L., Hepler, B. B., \& Kim, M. O. (2012). The Native Hawaiian and other Pacific Islander population: 2010. U.S. Census Bureau. Retrieved from http://www.census.gov/prod/ cen2010/briefs/c2010br-12.pdf 
Hughes, R. G., \& Marks, G. C. (2009). Against the tide of change: Diet and health in the Pacific Islands. Journal of the American Dietetic Association, 109(10), 1700-1703. doi:10.1016/ j.jada.2009.07.015

International Food Information Council Foundation. (2012). 2012 food and health survey: Executive summary. Retrieved from http://www.foodinsight.org/Content/3848/FINAL\% 202012\%20Food\%20and\%20Health\%20Exec\%20Summary.pdf

Jolliffe, D. (2011). Overweight and poor? On the relationship between income and the body mass index. Economics and Human Biology, 9(4), 342-355. doi:10.1016/j.ehb.2011. 07.004

Kifle, T. \& Desta, I. H. (2012). The relationship between body mass index and socioeconomic and demographic indicators: Evidence from Australia. International Journal of Public Health, 57(1), 135-42. doi:10.1007/s00038-011-0288-y

Kim, S. Y., England, L., Wilson, H. G., Bish, C., Satten, G. A., \& Dietz, P. (2010). Percentage of gestational diabetes mellitus attributable to overweight and obesity. American Journal of Public Health, 100(6), 1047-1052. doi:10.2105/AJPH.2009.172890

Lassetter, J. H. (2011). The integral role of food in Native Hawaiian migrants' perceptions of health and well-being. Journal of Transcultural Nursing, 22(1), 63-70. doi:10.1177/ 1043659610387153

Lassetter, J. H., \& Callister, L. C. (2009). The impact of migration on the health of voluntary migrants in Western societies: A review of the literature. Journal of Transcultural Nursing, 20(1), 93-104. doi:10.1177/1043659608325841 
Mau, M. K., Sinclair, K., Saito, E. P., Baumhofer, K. N., \& Kaholokula, J. K. (2009).

Cardiometabolic health disparities in Native Hawaiians and other Pacific Islanders. Epidemiologic Reviews, 31, 113-129. doi:10.1093/epirev/mxp004

McLaughlin, L. A., \& Braun, K. L. (1998). Asian and Pacific Islander cultural values: Considerations for health care decision making. Health \& Social Work, 23(2), 116-126. doi:10.1093/hsw/23.2.116

Metcalf, P. A., Scragg, R. K., Willoughby, P., Finau, S., \& Tipene-Leach, D. (2000). Ethnic differences in perceptions of body size in middle-aged European, Maori and Pacific people living in New Zealand. International Journal of Obesity and Related Metabolic Disorders: Journal of the International Association for the Study of Obesity, 24(5), 593599. doi:10.1038/sj.ijo.0801202

Moy, K. L., Sallis, J. F., Ice, C. L., \& Thompson, K. M. (2010). Physical activity correlates for Native Hawaiians and Pacific Islanders in the mainland United States. Journal of Health Care for the Poor \& Underserved, 21(4), 1203-1214. doi:10.1353/hpu.2010.0943

Neuman, M., Finlay, J. E., Smith, G. D., \& Subramanian, S. V. (2011). The poor stay thinner: Stable socioeconomic gradients in BMI among women in lower- and middle-income countries. The American Journal of Clinical Nutrition, 94(5), 1348-1357. doi:10.3945/ ajcn.111.018127

Pollock, N. J. (1995). Cultural elaborations of obesity - fattening practices in Pacific societies. Asia Pacific Journal of Clinical Nutrition, 4, 357-360.

Romero-Corral, A., Somers, V. K., Sierra-Johnson, J., Thomas, R. J., Collazo-Clavell, M. L., Korinek, J., ...Lopez-Jimenez, F. (2008). Accuracy of body mass index in diagnosing 
obesity in the adult general population. International Journal of Obesity, 32, 959-966. doi:10.1038/ijo.2008.11

Sarlio-Lahteenkorva, S., Silventoinen, K., \& Lahelma, E. (2004). Relative weight and income at different levels of socioeconomic status. American Journal of Public Health, (94)3, 468472. doi:10.2105/AJPH.94.3.468

Seniloli, K. (2005). They are digging their graves with their teeth. Journal of Pacific Studies, 28(2), 163-191.

Siefken, K., Macniven, R., Schofield, G., Bauman, A., \& Waqanivalu, T. (2011). A stocktake of physical activity programs in the Pacific Islands. Health Promotion International, 27(2), 197-207. doi:10.1093/heapro/dar026

Snowdon, W., Lawrence, M., Schultz, J., Vivili, P., \& Swinburn, B. (2010). Evidence-informed process to identify policies that will promote a healthy food environment in the Pacific Islands. Public Health Nutrition, 13(6), 886-892. doi:10.1017/S136898001000011X

Stafford, S. (2010). Caught between "the Rock” and a hard place: the native Hawaiian and Pacific Islander struggle for identity in public health. American Journal of Public Health, 100(5), 784-789. doi:10.2105/AJPH.2009.191064

Stevens, J., McClain, J. E., \& Truesdale, K. P. (2008). Selection of measures in epidemiologic studies of the consequences of obesity. International Journal of Obesity, 32, S60-S66. doi:10.1038/ijo.2008.88

Subramanian, S. V., Perkins, J. M., Ozaltin, E., \& Smith, G. D. (2011). Weight of nations: A socioeconomic analysis of women in low- to middle-income countries. The American Journal of Clinical Nutrition, 93(2), 413-421. doi:10.3945/ajcn.110.004820 
U.S. Department of Agriculture. (2012a). Official USDA food plans: Cost of food at home at four levels, U.S. average, December 2011. Retrieved from http://www.cnpp.usda.gov/ Publications/FoodPlans/2011/CostofFoodDec2011.pdf

U.S. Department of Agriculture. (2012b). Official USDA Alaska and Hawaii thrifty food plans: Cost of food at home ( $2^{\text {nd }}$ half 2011). Retrieved from http://www.cnpp.usda.gov/ Publications/FoodPlans/2011/CostofFoodAKandHI2011secondhalf.pdf

Wang, C., Abbott, L., Goodbody, A. K., \& Hui, W. Y. (2002). Ideal body image and health status in low-income Pacific Islanders. Journal of Cultural Diversity, 9(1), 12-22.

Wilkinson, J. Y., Ben-Tovim, D., \& Walker, M. K. (1994). An insight into the personal and cultural significance of weight and shape in large Samoan women. International Journal of Obesity and Related Metabolic Disorders: Journal of the International Association for the Study of Obesity, 18(9), 602-606.

World Health Organization. (2010). Controlling the global obesity epidemic. Retrieved from http://www.who.int/nutrition/topics/obesity/en/index.html

World Health Organization. (2011). WHO global infobase. Retrieved from https://apps.who.int/ infobase/Comparisons.aspx

World Health Organization. (2012). Obesity and overweight: Fact sheet $N^{\circ} 311$. Retrieved from http://www.who.int/mediacentre/factsheets/fs311/en/index.html

Worthy, S. L., Lokken, K., Pilcher, K., \& Boeka, A. (2010). Demographic and lifestyle variables associated with obesity. Health Education Journal, 69(3), 372-380. doi:10.1177/00178 96910363330 
Wright, J. D., Kennedy-Stephenson, J., Wang, C. Y., McDowell, M. A., \& Johnson, C. L. (2004). Trends in intake of energy and macronutrients, United States, 1971-2000. MMWR Weekly, 53, 80-82. Retrieved from http://www.cdc.gov/mmwr/preview/mmwrhtml/ mm5304a3.htm

Zimmerman, E., Holst, C., \& Sorenson, T. I. A. (2011). Lifelong doubling of mortality in men entering adult life as obese. International Journal of Obesity, 35. 1193-1199. doi:10.10 38/ijo.2010.274 


\section{Table 1}

Demographic Characteristics of Participants

\begin{tabular}{|c|c|}
\hline Characteristic & $n(\%)$ \\
\hline \multicolumn{2}{|l|}{ Region } \\
\hline Utah & $155(42.6)$ \\
\hline Hawaii & $209(57.4)$ \\
\hline \multicolumn{2}{|l|}{ Gender } \\
\hline Male & $131(36.0)$ \\
\hline Female & $233(64.0)$ \\
\hline \multicolumn{2}{|l|}{ Age } \\
\hline Mean (SD) & $39.0(15.2)$ \\
\hline \multicolumn{2}{|l|}{ Income } \\
\hline Less than 20,000 & $89(24.4)$ \\
\hline 20,000 to 39,999 & $104(28.5)$ \\
\hline 40,000 to 59,999 & $88(24.1)$ \\
\hline 60,000 to 79,999 & $42(11.5)$ \\
\hline 80,000 or more & $38(10.4)$ \\
\hline \multicolumn{2}{|l|}{ Education } \\
\hline Some high school & $14(3.8)$ \\
\hline Graduated from high school & $120(33.0)$ \\
\hline Some technical school or college & $124(34.1)$ \\
\hline Graduated from college & $74(20.3)$ \\
\hline
\end{tabular}


Attended some graduate school

Have a graduate degree

Marital Status

Married

Never married

Separated or divorced

Living with partner

Widowed

Ethnicity

Hawaiian

Samoan

Tongan

Other Pacific Islander

Health Insurance

Yes

No

Regular source of health care

Yes

No
325 (89.3)

$5(1.4)$

$26(7.1)$

213 (58.5)

$88(24.2)$

$40(11.0)$

14 (3.8)

$9(2.5)$

$222(61.0)$

74 (20.3)

$22(6.0)$

$46(12.6)$

$317(87.1)$

47 (12.9)

39 (10.7) 


\section{Table 2}

Body Mass Index Categories of all Participants

\begin{tabular}{|c|c|c|c|}
\hline Weight Category & $\begin{array}{l}\text { Overall } \\
(n(\%))\end{array}$ & $\begin{array}{c}\text { Male } \\
(n(\%))\end{array}$ & $\begin{array}{l}\text { Female } \\
(n(\%))\end{array}$ \\
\hline Underweight (BMI <18.5) & $4(1.1)$ & $0(0)$ & $4(1.7)$ \\
\hline Healthy $(\mathrm{BMI} \geq 18.5$ but $<25)$ & $53(14.6)$ & $12(9.1)$ & $41(17.6)$ \\
\hline Overweight $(\mathrm{BMI} \geq 25$ but $<30$ ) & $94(25.8)$ & $28(21.4)$ & $66(28.3)$ \\
\hline Obese $(\mathrm{BMI} \geq 30)$ & $213(58.5)$ & $91(69.5)$ & $122(52.4)$ \\
\hline *Morbidly Obese $(B M I \geq 40)$ & $61(16.7)$ & $23(17.6)$ & $39(16.7)$ \\
\hline
\end{tabular}

*Morbidly Obese is subcategory of Obese 
Table 3

Correlations of BMI and Demographic Characteristics

\begin{tabular}{lcc}
\hline & $r$ & $\mathrm{p}$ \\
\hline Age & .031 & .560 \\
Education & -.123 & $.018^{*}$ \\
Income & -.055 & .299 \\
\hline
\end{tabular}

*Significance of $\mathrm{p}<.05$ 
Table 4

Difference of BMI among Location

\begin{tabular}{lcccc}
\hline & $n(\%)$ & BMI Mean (SD) & t & p \\
\hline Overall & $155(42.6)$ & $33.73(7.97)$ & & $.017^{*}$ \\
Utah & $209(57.4)$ & $31.72(7.87)$ & & \\
Hawaii & & & 2.036 & $.039 *$ \\
Male & $65(49.6)$ & $34.77(7.18)$ & & \\
Utah & $66(50.4)$ & $32.20(6.93)$ & & \\
Hawaii & & & \\
Female & & & \\
Utah & $90(38.6)$ & $32.96(8.50)$ & \\
Hawaii & $143(61.4)$ & $31.50(8.28)$ & \\
\hline
\end{tabular}

$\mathrm{SD}=$ Standard Deviation

*Significance of $\mathrm{p}<.05$ 
Table 5

Difference of BMI among Gender

\begin{tabular}{lcccc}
\hline & $n(\%)$ & BMI Mean (SD) & t & p \\
\hline Overall & & & 1.725 & .086 \\
Male & $131(36.0)$ & $33.49(7.12)$ & & \\
Female & $233(64.0)$ & $32.06(8.34)$ & & \\
& & & \\
\hline
\end{tabular}

$\mathrm{SD}=$ Standard Deviation 
Table 6

Crosstabs of Samoans and other ethnic subgroups

\begin{tabular}{lccc}
\hline & $n(\%)$ & BMI Mean(SD) & $\mathrm{p}$ \\
\hline Hawaiian & $222(61.0)$ & $31.72(7.77)$ & $.00^{*}$ \\
Samoan & $74(20.3)$ & $36.54(7.59)$ & - \\
Tongan & $22(6.0)$ & $31.77(7.54)$ & .09 \\
Other Pacific Islander & $46(12.6)$ & $30.37(7.44)$ & $.00^{*}$ \\
\hline
\end{tabular}

$\mathrm{SD}=$ Standard Deviation

*Significance of $\mathrm{p}<.05$ 